PUblic ARChaeology, Vol. 7, No. 2, Summer 2008, 69-90

\title{
Evaluating Community Archaeology in the UK
}

\section{FAYE SIMPSON}

Department of Archaeology, University of Exeter, UK HOWARD WILLIAMS

Department of History and Archaeology, University of Chester, UK

Does community archaeology work? In the UK over the last decade, there has been a boom in projects utilising the popular phrase 'community archaeology'. These projects can take many different forms and have ranged from the public face of research and developer-funded programmes to projects run by museums, archaeological units, universities, and archaeological societies. Community archaeology also encapsulates those projects run by communities themselves or in dialogue between 'professional' and 'amateur' groups and individuals. Many of these projects are driven by a desire for archaeology to meet a range of perceived educational and social values in bringing about knowledge and awareness of the past in the present. These are often claimed as successful outputs of community projects. This paper argues that appropriate criteria and methodologies for evaluating the efficacy of these projects have yet to be designed. What is community archaeology for? Who is it for? And is it effectively meeting its targets? Focusing on the authors' experiences of directing community archaeology projects, together with the ongoing research assessing the efficacy of community archaeology projects in the UK, this paper aims to set out two possible methodologies: one of self-reflexivity, and one of ethnoarchaeological analysis for evaluating what community archaeology actually does for communities themselves.

KEYWORDS Community, Ethnoarchaeology, Shoreditch, Stokenham, Values

\section{Introduction}

'Community archaeology' has become a widespread label, reflecting the increasing number of archaeological projects explicitly designed for, or incorporating, substantial community involvement and participation. Community archaeology has also been extensively theorised, most recently as an element in a new paradigm conceptualising 
the relationship between the past and the present and the relationship between archaeology and 'the public' (Holtorf, 2006). However, to date there has been a lack of research into whether community archaeology projects are currently effective at achieving the desired and perceived benefits of community dialogue and participation in archaeology, and whether this translates into real effects on people's knowledge and perception of the past and subsequently their sense of identity. It remains unclear whether, beyond theoretical rhetoric and manifestos, many community archaeology projects currently taking place in the UK are fulfilling the values espoused by archaeologists when they were initially designed. It is particularly questionable whether the social outputs of community archaeology have any lasting impact beyond the duration of the projects themselves. In short, is community archaeology working?

Previous discussions of whether community archaeology works effectively have generally been based on general and proscriptive theoretical discourses supported by choice case studies (Marshall, 2002). In other words, they are based on ideal expectations of what community archaeology should achieve in terms of either educating and engaging the community or constructing community values and identities. They can include methodological check-lists of universal criteria for the effective running of community archaeology projects regardless of context (e.g. Moser et al., 2002; Tully, 2007). While these approaches provide useful statements of the potential of community archaeology and examples of their application, in the UK at least there have been few attempts to move beyond ideals and expectations to assess qualitatively and contextually how community archaeology projects work in practice.

Those evaluations of community archaeology projects in the UK have focused on visitor and participant surveys (Merriman, I99I; Streeter, 2005; Rosenfeld, 2006). Such studies have provided some informed generalisations about how different groups respond to community projects in different ways. They also illustrate how different types of community project investigating varied kinds of archaeological remains can impact on, and interact with, communities in contrasting fashions. However, quantitative methodologies have their limitations. They tend to be restricted by the structure of the medium they employ — namely, the formal questionnaire. This format can only elicit relatively formal and abbreviated responses. When quantified, such questionnaires lose much-needed nuanced and contextual data, simplifying and obscuring how archaeological projects engage and impact on communities (Newman, I995: 335 ).

Therefore, not only is more research required into the benefits of community archaeology, but also new methodologies are called for. In the UK, limited consideration has been given to qualitative and contextual approaches to evaluating the effectiveness of community archaeology projects. Theoretical and quantitative approaches have provided only partial perspectives on whether community archaeology projects really do 'work' for the communities they claim to be serving. Consequently, while there is a growing consensus that community archaeology is a 'good thing', the literature remains vague concerning how and to what extent community archaeology is currently effective in achieving its aims. In other words: Do community and outreach projects change the appreciation and knowledge of the past? In turn, does community archaeology create genuine opportunities for dialogue with, and the participation of, non-archaeologists? Does community archaeology 
affect community values and identities? Alternatively, is community archaeology simply an ideal or primarily a means for archaeologists to secure successful funds for their excavations by meeting self-defined criteria? These are all challenging questions that are difficult to answer in a quantitative and concrete manner. Yet they are key questions for all who claim to be participating in community archaeology. This paper will outline two methodological approaches, one of self-reflexivity and the other of ethno-archaeological analysis, that it is hoped may begin to address these questions.

The first method can be described as a self-reflexive approach. This involves a critical evaluation by archaeologists of their on-going projects based upon the accrued knowledge of long-term observation and engagement with projects and the communities in which they are situated. In this paper, two contrasting community projects directed by the authors at Shoreditch, London, and Stokenham, Devon, will be outlined and the lessons learned will be discussed. Neither project is portrayed as typical or as evidence of good practice; they are outlined here to illustrate the potential of self-critique to reveal poignant issues of wider significance to the efficacy of community archaeology projects.

The second method is to take an ethno-archaeological evaluative and comparative approach. The evaluative element of this method involves an external researcher observing and discussing a project's effectiveness through participation and dialogue with both community archaeologists and community members during the project's duration. The comparative element of this method involves conducting the same exercise with different community projects to assess how they fare in relation to each other. Examples of this work are presented, although the research into this method is ongoing and results are preliminary (Simpson, forthcoming).

In combination, these approaches aim to enable the critical deconstruction of the claimed and apparent outputs of community archaeology. It is hoped that these methods will be increasingly utilised alongside established quantitative surveys. They promise to identify the range of relationships between archaeological practice and community identities and values generated through community archaeology projects. Before considering these two methods in more detail, the scene will be set with a brief review of the origins, development, complexity, and diversity of community archaeology in the UK.

\section{The origins and evolution of community archaeology in the UK}

At one level, archaeology has always taken place within the social, political, and ideological contexts of contemporary society and encouraged public engagement at a variety of levels. However, the specific origins of the phenomenon known as 'community archaeology' in the UK can be found in the last thirty years and the changing environment of theory and practice (Marshall, forthcoming).

The development of a self-defined 'community archaeology' within public archaeology was, in part, facilitated by an intellectual shift from 'processual' to 'post processual' archaeology (Hodder, 200I: I; Marshall, 2002). This led to a philosophical move from absolutism to relativism in theoretical archaeology in which the authority of professional archaeologists was challenged together with the existence of a single, true reading of the past (Blackburn, 2006). It has also sprung from worldwide debates 
in post-colonial contexts, principally indigenous rights movements and the ethical considerations and methodologies required for working with these communities. This theoretical shift was underway from the I980s, and subsequently found further support in the UK within the changing political climate of the late I99os. With a move from a Conservative to a New Labour government with its neo-liberal focus on the creation of social values, inclusively as well as through a sense of pride in communities through democratic socialism, community archaeology has found political and financial support at many levels (Schadla-Hall, I999: I52; Pluciennik, 200I; Accenture, 2006: 6; see also the Labour Party website http://www.labour.org.uk/ labour_policies). Therefore, the rise of community archaeology has involved a philosophical shift as well as a transformation in the balance of power and financing of British archaeology. Community archaeology epitomises the current political environment, where the focus is placed upon enabling communities rather than preaching to them.

This multi-causal socio-political context of community archaeology has undoubtedly also caused conflicts and tensions, and has both negative and positive implications for the practice of archaeology (Marshall, forthcoming). The future development of community archaeology will inevitably rely upon a balance between professional archaeological expertise and research agendas on the one hand, and answering the voices of communities themselves on the other (cf. Moshenska et al., 2007). Having said that, the reason why community archaeology remains problematic is that it has always been about doing archaeology rather than theoretical concepts. When theories or manifestos are espoused, they tend to be detached from the very fundamentals of archaeological practice that are the core of community archaeology. Hence, the future of community archaeology focuses on its role in action', by delivering projects that are both proactive and reactive to public values, rather than monolithic definitions and theoretical dogma.

Many of the concepts and core themes behind community archaeology derive from the more broadly discussed practice of public archaeology. This can be seen in the themes prevalent in some of the earliest work on public archaeology. For example, the first book entitled Public Archaeology (McGimsey, I972) recognised the need for archaeologists to provide a public service, through awareness of and engagement with the public in archaeological work, but perhaps most importantly also recognised the need to encompass public values and ideas (McGimsey 1972). However, subsequently the phrases 'community archaeology' and 'public archaeology' seem to have been used conjointly and alternatively (Liddle, I989; Smardz, 2000), perhaps due to the lack of a clear definition of both.

Therefore, like public archaeology, community archaeology in its broadest sense concerns serving and communicating archaeology to the wider public - to people outside the profession. Recently it has been defined on Wikipedia as archaeology 'by the people for the people' (http://en.wikipedia.org/wiki/community_archaeology, 2007). This idealised concept of community archaeology, the idea of it being initiated and controlled by the people for the people, is something of a naïve fantasy. In reality, community archaeology is censored and manipulated, and communication of information and access to the past is controlled through many different agencies. It is a nexus between politicians, professionals, and a variety of interest groups as well 
as the multifarious 'public'. Despite the aspirations for a 'bottom-up' democratized community archaeology (e.g. Moshenska et al., 2007) which many projects espouse, such as the Sedgeford project (Faulkner, 2005; Moshenska, 2005), it inevitably retains many 'top-down' elements, which both overtly and covertly influence the kinds of projects that receive funding and support.

Therefore, not only does the simple phrase 'community archaeology' encapsulate a plethora of motivations behind its use and application, all of which are specific to the community in question (Marshall, forthcoming) - the phrase is also a theoretical and political one that, in the UK, has become popular because it resonates with the contemporary socio-politics of Britain's New Labour government and its aspirations to social inclusivity (Lammy, 2006). It is used to create and maintain particular kinds of aspired-to identities for the British people. It is also a means of portraying (rightly or wrongly) a politically acceptable image of public accountability and engagement for what is in fact an increasingly popular subject, but at the same time an increasingly exclusive profession in which the amateur struggles to find a place (Faulkner, 2005). The benefits of community archaeology to archaeology as a whole cannot therefore be underestimated, providing economic support and social acceptance for archaeological enterprises and archaeological identities (both for practitioners and community identities bolstered through connections with material pasts). Therefore, regardless of what, if anything, community archaeology does for communities, in the current UK climate it certainly has become a winner for archaeologists! Inevitably, though, community archaeology defies precise definition and cannot be easily summarised in a check-list. In other words, it resides in a diverse range of practices and activities rather than a single theoretical or political agenda.

Despite the fact that this context might lead the cynic to regard community archaeology as simply a diffuse and varied response to recent socio-politics, the often-hidden agendas of community archaeology frequently have a real and substantive contribution to make beyond professional self-aggrandizement. However, it is these values that have yet to be fully identified and assessed. Can community archaeology projects create, change, and even increase the value of the heritage outside the profession? Are archaeologists really giving the public what they want through these projects or do they fail to meet the aims of the funding bodies, politicians, and archaeologists? Is this just archaeology paying lip service to providing a public service?

It is therefore vital for the future of community archaeology that archaeologists critically evaluate the real, tangible and intangible, values generated and facilitated by community archaeology projects. If the archaeological community is to keep justifying the millions of pounds that are being invested in these projects by the likes of the Heritage Lottery Fund and (directly and indirectly) by the UK government, the character of the way these projects are deemed 'successful' must be appraised from both theoretical and practical perspectives.

\section{Community archaeology's definition and parameters in the UK}

The problems with defining the term 'community archaeology', and therefore its lack of formal definition, should not be seen as simply an academic hang-up. A hazy definition is an integral part of community archaeology's very nature and this enables 
a plethora of approaches and activities to fall under its banner. Community archaeology projects might include (but not solely) restoration, field-walking, standing building surveys, oral history projects, school-based programmes, finds-training, archive research, and excavation (Liddle, I989; Jameson, 2004; Oswald, 2007). Community archaeology can involve the investigation of all periods of the past from earliest prehistory to the twenty-first century with equal effectiveness. Moreover, community archaeology projects can operate in varied environments in urban and rural settings, may involve different age, gender, socio-economic, and ethnic groups, and may incorporate areas with different cultural and socio-economic histories and environments.

What constitutes a community archaeology project also varies according to who is involved. It might be a term applied to projects designed primarily for research, for student training, or in developer-funding contexts that have 'outreach' elements. At the other end of a spectrum it can be taken to mean projects designed by and for the community with little or no professional involvement and guidance. These include projects run by local historical and archaeological societies, like the community archaeological excavation in Hendon run by Hendon and District Archaeological Society members (Moshenska, 2007a). In between these extremes are a range of contexts involving a variety of relationships between archaeologists and communities, including projects facilitated by archaeological societies, museums, universities, and field units. Cross-cutting this institutional variability, funding sources can be equally diverse. From governmental and national funding bodies to charitable donations and local people themselves, the money for community archaeology can derive from multiple sources.

This breadth of definition allows numerous outreach projects to claim the label of community archaeology. It is therefore argued that it is not an academic, professional, and political failure to define what community archaeology is that needs to be addressed - instead, the focus should be on who the community are and what they want from and value in these community archaeology projects. In other words, working towards a clear, exclusory, and purist definition of community archaeology's parameters is not particularly profitable in practice. Instead the complexity and diversity of community archaeology should be embraced as part of its key characteristics, allowing public archaeology to be integrated into a range of socio-political, economic, and religious environments. Of more pressing concern, the next critical step forward for community archaeology lies not in definition but in public efficacy. It is certainly vital to deconstruct community archaeology, and understand the complex theories that motivate its application. However, it is more pertinent to focus on the values associated with this approach, both externally in dealing with the public and internally within the archaeological community.

\section{To dig or not to dig?}

The All Party Parliamentary Archaeology Group claimed in 2003: '[T]he public's perception of the purpose and practice of archaeology is too narrowly focused on excavation' (APPAG, 2003: D46). It is true that public perceptions, reinforced by the media, focus on excavation and discovery, but this is because viewing figures and 
surveys suggest this is what the public want (Merriman, I99I; Piccini and Henson, 2006: I4). Despite this, excavation is still the one thing archaeologists, deliberately or not, exclude the public from. APPAG (2003), along with other archaeologists, (Hawkins, 2000: 20I) suggest that archaeologists should encourage the public to engage in alternative participatory activities, to understand the historic environment through its most accessible and tangible elements before they are persuaded to 'reach prematurely for their spades and trowels' (Oswald, 2007: 20). Case studies of this type of community project can be seen all over the United Kingdom (e.g. see http://www. britarch.ac.uk/communityarchaeology).

It is undeniable that this multi-dimensional approach, in which the public can experience all aspects of the heritage, is vital, but these activities should not be used as substitutes for excavation. Excavation remains a vital component to community archaeology's image and people's involvement in community archaeology projects. This is partly because of the popular public image of archaeology. Excavation is something the public already has an association with and feels comfortable with (Jameson, 2004; Lucas, 2004). Furthermore, digging offers an experience, the thrill of discovery, and it is this that modern society craves (Holtorf, 2005, 2006). It is through the marketing of this 'hook', to gain and maintain interest in projects and heritage in general, that 'digging' remains so important in community archaeology. Excavation has also been claimed to have psychological benefits, the finding of objects a metaphor for finding oneself; in a Freudian sense, digging and discovery are a metaphor for self-discovery — 'to dig deeper into one's own mind' - and a form of therapy (Holtorf, 2005). Therefore this activity has the ability to make (or maintain) archaeology's popularity, through proactively engaging people in something tangible.

Educationally, excavation has been claimed to be a powerful learning tool for both school-based learning and higher and continuing education, whether the methodological approach is formal or informal. It has been argued that archaeological excavations enable learning through doing, thinking, and feeling, and therefore transfer maximum knowledge most effectively to the widest range of people (Jameson, I997).

Therefore, while all proactive approaches to engaging people in archaeology have archaeological and (potentially) social value, it is undeniable that excavation forms an intrinsic and vital component of community archaeology.

\section{Two methods of evaluating community archaeology}

Having set the scene by introducing the key issues surrounding the definition and parameters of community archaeology, this paper now proceeds to consider two qualitative methods for assessing the efficacy of community archaeology projects. The first, a self-reflexive approach, is discussed in detail, as it draws on the authors' own experience of community archaeology projects. The second, an ethno-archaeological methodology for accessing community archaeology, is only briefly discussed as a method for future study, and should provide a less biased approach to assessing community archaeology. This brevity is because the method forms a part of ongoing doctoral research. It is included here because it offers tantalising scope for the future analysis of community archaeology. 


\section{Evaluation by self-critique}

An integral element of post-processual archaeologies has been the desire for archaeological theory and practice to be self-reflexive. An awareness of one's own biases and the contexts within which archaeological knowledge is produced is an essential component of modern archaeological theory and practice. However, particularly in a culture of funding applications with clear targets and outputs, self-reflexivity can be regarded as a form of weakness. In particular, it can be regarded as showing the limitations of work done and as opening the project and the researcher up to external criticism (Hodder, 2000; Edgeworth, 2006). Certainly, self-appraisal remains open to the bias that only successes will be recognised. However, for a progressive development of community projects to take place, there is a need for a degree of honest self-critique to identify those areas where improvements might be made. This approach, in turn, promises to facilitate the refinement of the theories and methodological approaches of future community archaeology projects.

Two contrasting case studies have been selected to illustrate the potential of this approach. This selection was based on the authors' experiences; the projects involve different approaches to contrasting archaeological sites in very different communities. The results demonstrate diverse and contrasting experiences of community archaeology, and serve to illustrate the importance of a contextual approach to evaluating its impact on communities.

The Museum of London: a city experience In 2005-2006, the Museum of London was funded by the Big Lottery Fund's 'Their Past Your Future' programme to create a community project. The work was directed by one of the authors, Faye Simpson (FS), for the Museum of London, and was grant-managed through the Museums, Libraries, and Archives Council with support from Hackney Council and the Shoreditch Trust. The project undertook a community archaeology excavation in Shoreditch Park, Hackney, London. Prior to World War II this had been an area of high-density Victorian working-class housing. During London's Blitz large numbers of houses were destroyed by bombs and subsequently levelled to make way for the modern park (Aitken and Simpson, 2005). The project aimed to explore the nature of the community prior to World War II, as well as the effects of the German bombing: the Blitz period remains an important part of the community's remembered history and identity (Simpson and Keily, 2005, Figure I).

Part of the attraction of this site for the Museum of London was its location in inner-city London, an area known for its socially and ethnically diverse population, high crime rates, and high percentage of socially and economic disadvantaged groups (referred to as groups C2D\&E; Aitken and Simpson, 2005). Therefore, in political terms the project fitted the Museum of London Group Diversity Strategy 2005-20I0, for reaching new audiences outside the usual museum visitor demographics. This provided the project with the support of the directors of the museum, which allowed access to the expertise, staffing, and resources of a large and respected professional archaeological unit and museum.

The project also fitted in to the Museum of London's research programme 'The Biographies of London Life'. This program examined seventeenth- to twentiethcentury London through material culture; this period has been under-studied by archaeologists in the United Kingdom in terms of urban life and society. Shoreditch 


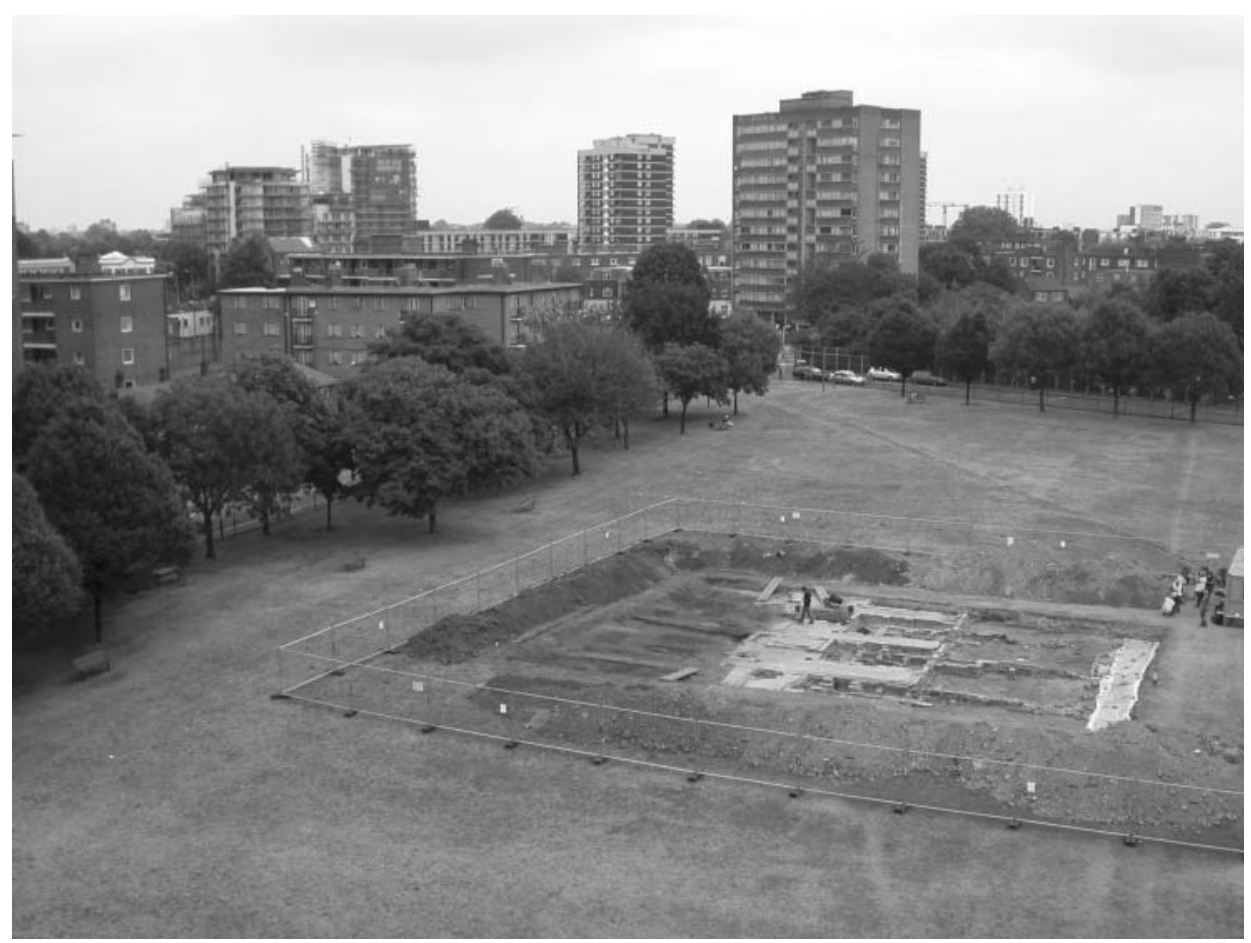

FIGURE 1 Aerial view of Shoreditch excavation illustrating its context within the park and its urban context, July 2005 (Photo (C) Faye Simpson).

was a site which could demonstrate the value of examining the material culture of recent centuries as a primary medium for interpreting the past, rather than as a supporting medium to illustrate text-based narratives. The project also served national government agendas in commemorating the sixtieth anniversary of the end of World War II, and fitted in with plans by Hackney's local authority plan to create a useful park. By offering an opportunity to turn an under-utilised area into a recreational space, the project met All Party Archaeology Group and Department of Culture Media and Sport plans to make heritage more inclusive for London communities.

The aims of the project were broad: to provide through excavation within a community a socially inclusive and relevant archaeological and historical project that directly engaged and involved local people. The project aimed to enable local people to interpret their heritage, and through this involvement and knowledge to provide them with a sense of pride in their local environment. It was hoped that the project would bring together a diverse community through a common goal and activity, therefore enabling a sense of social cohesion. It also provided an educational tool both for life-long learning and for school education programmes, allowing students to learn about World War II, local history, and the job of an archaeologist through practical experience.

During the project, the success of this two-year venture was assessed by the Museum of London and the Lottery Fund quantitatively through visitor numbers. Figures indicated that the project attracted over 3000 visitors, with over 700 local 
people participating in the excavation (Figure 2) and subsequently it was claimed by the organisations and sponsors that these figures indicated clear interest in archaeology and local heritage by the community. Critical analyses indicated that these high numbers were due, in part, to the excavation's urban location: it was situated in one of the few open spaces in the area, surrounded by housing tower blocks. This was supported by the fact that the park was a thoroughfare for the community's city workers. The focus upon relatively recent history, within the living memory of the eldest members of the community, and perhaps also the association with the war (a popular topic, not least for local school groups), also enhanced the popularity of the project. A limited qualitative survey was also conducted, focusing on participatory visitor enjoyment of the project (Streeter, 2005). The results of this survey suggested a resoundingly positive response. However, the survey did not assess the opinions of the majority of people who visited rather, than got involved, in the excavation. Similarly, like the quantitative surveys, the qualitative survey gave no indication as to whether opinions changed, and what impact this project had on people's values regarding their heritage.

In critical terms, assumptions were made, in part by FS, that excavation was key to successful outreach. This reflected FS and her colleagues' background in field archaeology and their experience of excavation. There was public and political consultation prior to the excavation in which support was voiced, but critically this was really a matter of marketing an idea already in place. Ideas were drawn together

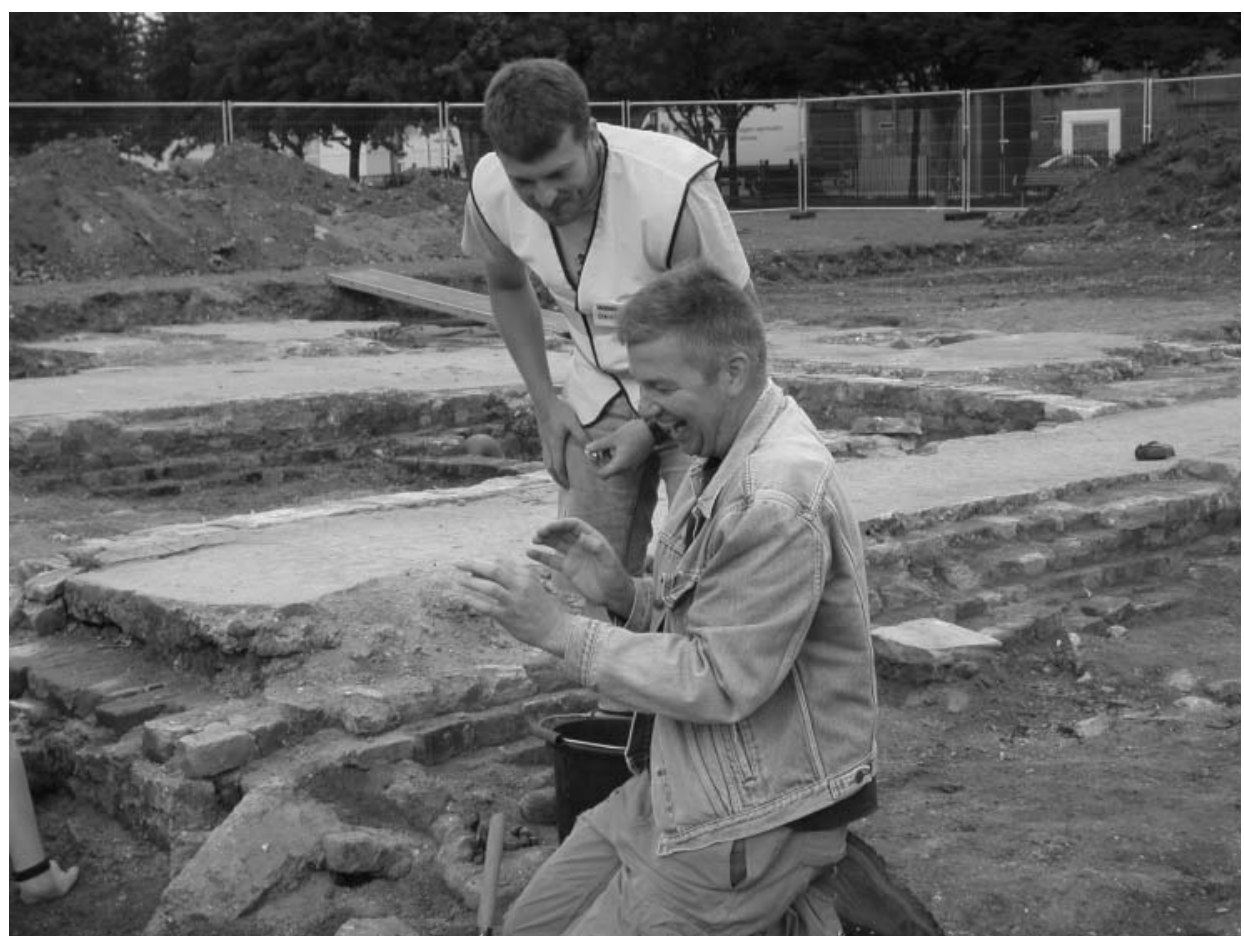

FIGURE 2 A local resident involved in the Shoreditch Park excavation (Photo (c) Faye Simpson). 
for peripheral activities beyond the excavation influenced by the public themselves, but the core of the project was designed by, and for, the research and community agendas of professional archaeology and influenced by agendas and financial support from various tiers of government.

For a temporary period during the community excavation in July 2005 and 2006, when the project was part of Shoreditch's youth festival, the project did offer a focus for the community. Its location and support encouraged and enabled socially and ethnically diverse participation. The oral history component of the project was especially successful in bringing together the community, with the older generations able to share stories about their experiences with younger generations (Moshenska, 2007b). It can also be argued that its success related to Time Team's support (Figure 3), including the resources and logistics that this Channel Four television programme brought with it, including the facilities to research and access information and people and to communicate successfully to a wide audience both within and outside the local community, especially in disseminating the results of the project. The only minor restriction in this regard was that the Time Team programme was screened in 2007 - almost two years after filming in 2005 and after community interest had died down.

Indeed, a clear limitation on the project's wider social impact was that interest in the project waned after the excavation finished. This was not a problem in relation to the initial application for the Big Lottery Fund's 'Their Past Your Future' grant,

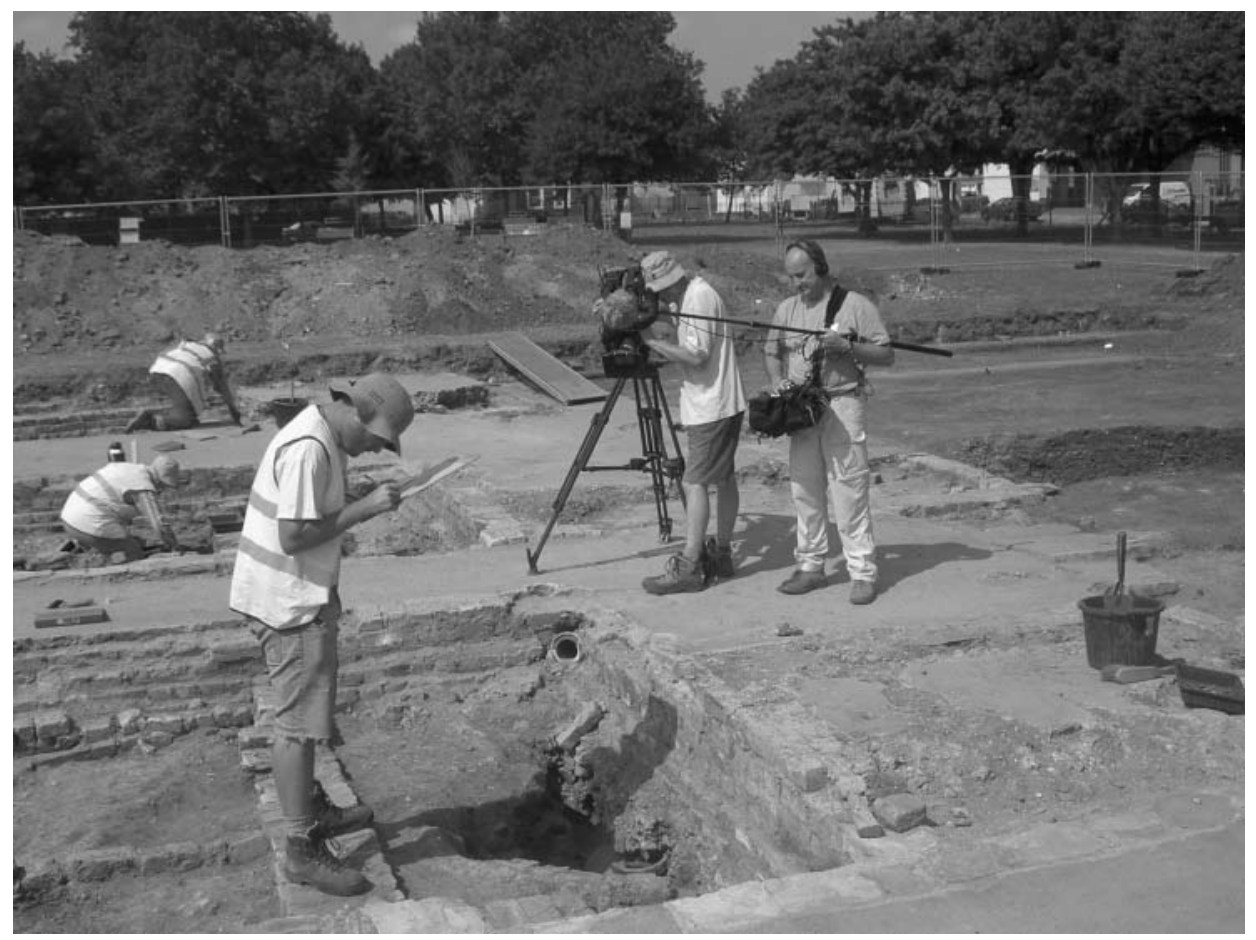

FIGURE 3 Channel Four's Time Team filmed the excavation of a nineteenth century tenement in Shoreditch Park, July 2005 (Photo (C) Faye Simpson). 
which provided funding for the commemoration of the sixtieth anniversary of the end of World War II and for hosting the exhibition at the Museum of London for a short period in June and July 2005. From the perspective of this application, sustainability was not a primary output. However, in the subsequent bid for funds it was an explicit objective to encourage further interest in the heritage of the Hackney community and build on the work of the excavation. More positively, local people taking part in 2005 did return to get involved in the subsequent year's excavation, but this only goes to prove that it was the excavation itself that was the draw. It was disappointing that there was a lack of participation in subsequent non-excavation activities. Ongoing research by FS has identified this failure as regards sustainability as a widespread problem experienced by many other community archaeology projects. Indeed, across both the UK and US, those involved in community archaeology have commented on this difficulty while retaining sustainability as a persistent objective for many projects (Simpson, forthcoming).

This brief review indicates that, for many people, the excavation was key to interest in this project. Whether that consisted of simply watching the process or practically engaging in it, once the digging ended, local interest evaporated. The theatre of the excavation was subsequently memorialised in the Time Team project and local people may have benefited from the experience of being there and (for some) taking part. However, it is difficult to evaluate whether there was any concrete and enduring influence on community knowledge and engagement with heritage, never mind any influence upon individual and group identities.

More positively, there were permanent results and there was some evidence of the effects of the excavation upon the local community. These included Hackney Museum setting up an exhibition relating to the site and the archaeology of World War II after the excavation was complete. This included much of the material found during the excavation, in an attempt to build upon the work of the excavation and hopefully increase visitor figures. However, visitor figures showed a dramatic decline following its opening. Furthermore, the park itself was redeveloped; signs were erected and pathways followed the path of old streets hidden beneath the ground. This was a positive but non-engaging step. It does at least help to remind the public of what is beneath their feet and perhaps of their experiences in the summers of 2005 and 2006.

The project also highlighted major financial issues for this type of externallyfunded community project. The grants had finite timescales and therefore, without further funding, subsequent projects had a very limited time span and have proved unsustainable to date. Like many other community archaeology projects, getting this project off the ground, and its relative success, was based on being supported by and located within a large organisation. This enabled many of the costs for staffing and resources, including that of paying for a community archaeologist, to be covered.

X-Arch and Stokenham: a rural experience Howard Williams' (HW) experiences of the ongoing X-Arch project provide both comparisons and contrasts with the experience of FS with the Shoreditch project.

The three-year X-Arch project (2006-2009) is a university-based community project funded by the Heritage Lottery Fund. Building off a successful earlier project directed by Tony Brown and Frances Griffith, in terms of its approach if not its precise 
parameters and focus (Brown et al., 2004), the project was designed by Sean Hawken and HW and directed by HW from March 2006 until February 2008. The project takes a two-pronged approach.

First, rather than setting up a single community dig, X-Arch has been concerned with facilitating a range of projects directed by local societies and communities themselves. Moreover, rather than having a single geographical focus, these projects are situated across Devon in different rural communities. These communities are varied but all contain a diverse socio-economic profile incorporating farm-workers and local businesses as well as commuters and retired people. In addition to the rural context, the principal differences from the Shoreditch project can be seen in the limited ethnic diversity and the heavy bias towards older individuals taking an interest in the archaeological projects (Aitken and Simpson, 2005). Currently X-Arch is supporting bottom-up initiatives by local societies at Bow, Brayford, Hartland, Membury, Sampford Peverell, and Widecombe-in-the-Moor. The nature of X-Arch support required by each community varies and is directed by the communities themselves. In practice, the support provided consists of guidance from trained archaeologists and the provision of specialist equipment, principally geophysical survey gear.

At the time of writing (February 2008), the projects have focused upon nonintrusive investigation of a range of prehistoric and early historic sites, including many that promise to produce new archaeological knowledge of Devon's past that will be of value to researchers as well as local communities. In the final year of the $\mathrm{X}$-Arch project, the aim is to support some of these groups in small-scale excavation of sites identified through geophysical survey with the help of X-Arch resources and expertise at Brayford and Hartland.

Second, to combat the traditional demographics of archaeological interest in the rural south-west, X-Arch explicitly aims to bring archaeology to schools in Devon by a variety of means. Schoolchildren are engaged with archaeology through workshops and activity days based at the schools themselves, and through activities based in the Department of Archaeology on the University of Exeter's Streatham campus in Exeter. Department-run fieldwork projects in rural Devon at Stokenham (2006 and 2007) and Oldaport (2007) have been used as a focus for further school activity days.

Overall, X-Arch is different from the Shoreditch project in many ways. Rather than operating on a single site it involves multiple contexts: the university itself, schools, and at least seven archaeological programmes. X-Arch responds to what communities and local societies themselves wish to achieve. In this sense it could be perceived as concerned with enabling and facilitating community archaeology rather than providing a top-down approach. By having multiple foci across the large county of Devon, the $\mathrm{X}$-Arch project is able to access and influence multiple communities rather than a single location. X-Arch aims to meet communities' training needs, provides equipment, and assists with the work. It also engages with local schools and therefore takes archaeology beyond those who were already dedicated enthusiasts. Rather than 'mock' excavations, X-Arch gives schoolchildren hands-on experience with real archaeological equipment, artefacts, and sites.

A further difference between X-Arch and the Shoreditch project is X-Arch's facilitation of archaeology programmes that build upon communities' established interests in their heritage and liaison with local historical societies. This approach allows 
for a degree of sustainability, by supporting and transferring knowledge and skills to community members.

The two related elements of the X-Arch project (community project support and involvement with schools) are ongoing and cannot be fully evaluated in this short paper. However, one element of X-Arch can be assessed. X-Arch has supported fieldwork at Stokenham in south Devon, incorporating both community projects and schools activities, directed by HW. This fieldwork was initially a research-led excavation (Williams and Turner, 2005) and the research focus has been maintained by investigating the origins and development of Stokenham village from prehistory through the Middle Ages to the present day. To date there have been three field seasons, in 2005, 2006, and 2007, with X-Arch supporting the 2006 and 2007 seasons. This research has incorporated a wide range of activities involving undergraduate students and local volunteers, including field-walking, geophysical and topographical surveys, test-pitting, a churchyard survey, and a survey of war memorials in the parish, in addition to open-area excavations at three sites in and around Stokenham village. From the project's inception the fieldwork has fulfilled the requirements of, and received funding from, the Department of Archaeology's student fieldworktraining programme. Further support was received from the Medieval Settlement Research Group.

From the outset, the research and training aims of the Stokenham element of the X-Arch project were supplemented by a community focus. Indeed, prior to the initiation of the X-Arch project, the fieldwork conducted at Stokenham was inspired by a pressing community need. Rather than taking an interest in the past, or in the preservation and conservation of a heritage site, the local community was concerned primarily with ensuring the extension of the current churchyard, the parish's primary focus for mortuary practice and the commemoration of the dead (Williams and Williams, 2007). Few spaces for graves remained in the churchyard without resort to the unpopular choice of reusing old graves. In a dispersed parish with a large elderly population, the funerary and commemorative importance of the churchyard extends beyond those who regularly worship within the church.

To remedy the situation, the church of Stokenham purchased an extension to the churchyard to the east, in the neighbouring Manor Field, where in the late twentieth century two earlier burial plots had been established. Given the known archaeological features in this field, thought to relate to the medieval and Tudor manor site, a stipulation of the planning process by Devon County Council was for an archaeological evaluation prior to the consecration and use of the purchased land for burial. Evaluation work by Exeter Archaeology revealed medieval features (Turner and Williams, 2005; Williams, 2007a) and Devon County Council subsequently stated that a requirement of the planning permission for the churchyard's extension was the total excavation of the area to be affected by the insertion of new graves. Without the finances to pay for a professional excavation, local people approached the University of Exeter to invite them to undertake the work as a research and training exercise (Turner and Williams, 2005; Williams, 2007a; Williams and Williams, 2007).

Therefore, regardless of any subsequent community participation and engagement or indeed the nature of the archaeology uncovered, the very context of the project 
fulfilled an important community-focused social and religious need, albeit a nonarchaeological one. Indeed, in meeting this community aspiration, the project engaged the community in a way that would not have been possible if the primary community interest was in the discovery of their past.

The community project at Stokenham could be evaluated on this criterion alone: namely the desired outcome of the churchyard's extension. Indeed, the results of the archaeological work in 2005 and 2006 led to the fulfilment of planning requirements and the consecration of the churchyard extension in the autumn of 2007. The centrality of the churchyard extension to community support was made even more apparent by the experience of the 2007 season. In this third season, excavations moved away from the area of the proposed churchyard extension. While the public-focused and school-related activities were successful in this season (see below), levels of local support declined, given that the dig was no longer principally working towards the churchyard's extension. This was in spite of the fact that in the 2007 season the archaeological remains of the manor house provided a richer and visually more impressive archaeological experience for volunteers and visitors than the artefact-poor peasant dwelling investigated in 2005 and 2006 !

If evaluated in terms of community activities, Stokenham might be also regarded a success. During the 2006 and 2007 seasons, in which the Stokenham project was supported by X-Arch, there was a range of community activities including numerous school visits and community participation in various archaeological activities (Figure 4). A key premise of the work was to allow people of all ages to participate in the full range of archaeological work, not simply the traditional demographic of local archaeological societies. These activities aimed to engage the community in a range of archaeological methods and techniques, of which excavation was but one. Moreover, given the community's interest in ensuring the presence of a useable churchyard without re-using existing graves, the integration of a churchyard survey into the project aimed to connect the archaeological research with the community's established priorities. It also provided a context for exploring popular perceptions of mortuary archaeology (Williams, 2007b; Williams and Williams, 2007; Walls and Williams, forthcoming; Williams, forthcoming). Therefore community elements were incorporated with the training of undergraduate archaeology students and a multi-faceted research agenda investigating medieval settlement and post-medieval commemoration.

However, despite these successes, the Stokenham element of the X-Arch project failed to engage the local community fully. Most locals preferred to visit rather than participate, partly because of the elderly age profile of the community but also in part because the work was seen as a 'service' to the community by others (students, university, professionals, etc.), rather than something they generated themselves and over which they had ownership.

This lack of participation may have also related to the nature of the parish's perception of the past. Stokenham church, itself of medieval origin, is situated at the heart of the community. There are innumerable other historical buildings throughout the parish including houses, cottages, and farm buildings. There was an observed awareness of the historic character of the South Hams landscape itself among the community. However, the identity of the community very much rested on more recent 

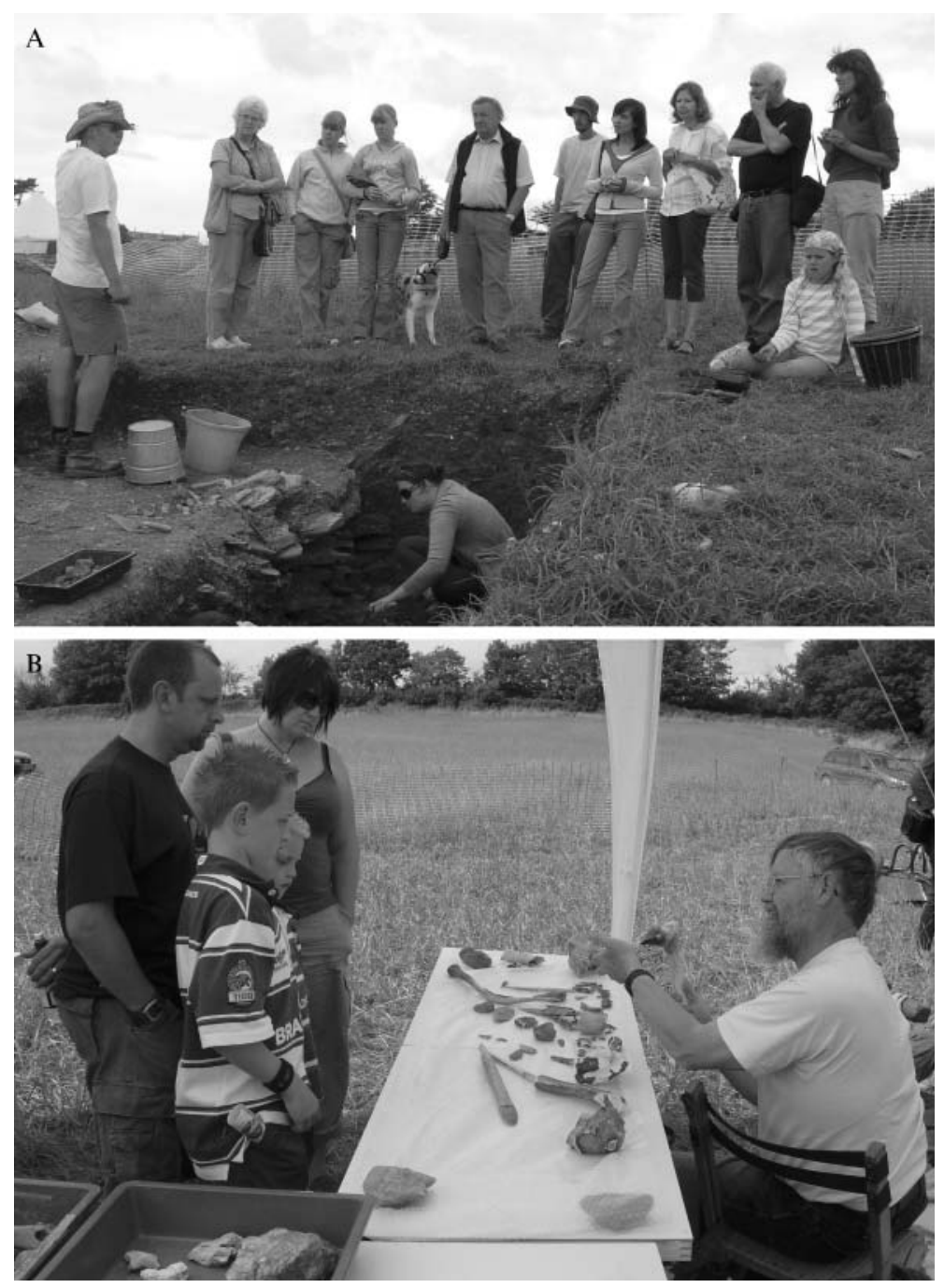

FIGURE 4 Two shots of community activities during the third Stokenham field season, July 2007: (a) a site tours; (b) a demonstration of flint knapping during the Stokenham 2007 open day by Professor Bruce Bradley (Department of Archaeology, University of Exeter). (Photos (c) Howard Williams).

events. In particular, the distinctive role of the South Hams during the latter half of World War II constitutes a common focus for community history for Stokenham and neighbouring parishes. War memorials, local books, and the discussions of local people all point to the fact that the parish's history is dominated by the evacuation of local people to make way for US Army D-Day training exercises. Meanwhile, the American war dead of these exercises appear to serve as adopted ancestors providing an important commemorative focus for this retirement community. The evacuation and war dead in combination provide a common history, for local families and for those from diverse geographical origins who have moved or retired to the area. The 
church, churchyard, and war memorials afford a materialised focus for these social memories alongside the commemoration of deceased family members and friends (Williams and Williams, 2007; Walls and Williams, forthcoming).

Given this context, the archaeological discoveries in Manor Field relating to the Middle Ages sparked the interest of local people but did not seem to generate any strong or personal affinity related to place or ancestry. Consequently, that the project enhanced perceptions of, and engagement with, the community's history, while accurate, was not the principal outcome of the archaeological fieldwork. Indeed, many of those most interested in the dig came from elsewhere in Devon and were already archaeology enthusiasts and members of groups such as the Young Archaeologists Club, the Council for British Archaeology South-West, and the Devon Archaeological Society. In this sense, the Stokenham element of the X-Arch project contributed to archaeological knowledge and community engagement in a modest way on a regional scale rather than in a local context. In addition, some visitors to the fieldwork were holidaymakers and hence temporary residents in the region. For them, the fascination with the past was more generic; it came less from local residence and affinity than — given the resonances the dig provided — from a more general knowledge of history.

Therefore, despite the numerous local benefits to schools and the community provided by the fieldwork, incorporating both an awareness of local heritage and securing the churchyard's commemorative future, it is untenable to view the Stokenham element of the X-Arch project as anything more than partially successful as a community archaeology project. The fieldwork contributed to a community's sense of identity by securing a site of future commemoration rather than a common past. Moreover, given the community's response to the work as being a 'service' provided by outsiders rather than a project they ran for themselves, it was anticipated that the interest in archaeology is unsustainable now excavations have ceased. The school activities at Stokenham, while of clear educational benefit, were also unsustainable once the project ceased. Ironically, it may be in the smaller-scale guidance and support offered by X-Arch to community-run fieldwork elsewhere in Devon that the project will create a more sustainable legacy.

Summary It is undeniable that both these projects enjoyed key successes linked to their project designs. Both the Shoreditch project and the Stokenham element of $\mathrm{X}$-Arch combined research, training, and community engagement. They addressed a range of local community values - some were planned for and others were not expected. Both projects engaged archaeology with the community social memories and commemorative spaces (Holtorf and Williams, 2006). It is hoped that this brief review of these two projects shows the potential of critical self-evaluation to highlight issues and concerns for future community archaeology projects to take on board and seek to overcome, in ways that appraisals of published results by individuals not involved in the project cannot easily achieve (see Tully, 2007).

\section{Evaluation by external appraisal and comparison}

The full results of the second methodological approach cannot yet be presented, but the approach demands our attention as a second avenue for evaluating community 
archaeology. Equally contextual, this method aims to avoid the biases of selfevaluation and forms the basis of ongoing doctoral research assessing community archaeology projects from an external perspective. The work is being conducted by FS within the X-Arch project directed by HW (Simpson, forthcoming). Here, only a brief review of the rationale and methodology of this work will be outlined.

It is argued that in order to access the values attached to community archaeology, specifically during community archaeology excavations, methodology should be based on an ethno-archaeological approach - that is, focused upon qualitative analysis rather than scientific and quantitative methodology. The reasoning behind this is that values relating to heritage are complex, and are a mixture of the tangible and the intangible, of the quantifiable and the unquantifiable interlinked with one another. These cannot be revealed by quantification alone. This approach includes assessing community values through participatory observations and conversations around flexible guidelines, rather than via formal questionnaires.

The methodology involves auditing numerous community archaeology projects that include excavation. The projects are analysed from start to finish. This is essential in order to understand the development of ideas and motivations, and to enable changing values to be assessed. It also allows an analysis of the effects of a project on wider social values within the communities in question. In some cases, this may argue against the expenditure and characteristics of the project, at least in its current form.

The initial aim was to focus upon a single project and follow it from start to finish in a manner equivalent to anthropological work. However, a pilot study showed that it was necessary to visit and collect data from a larger sample of projects, to identify variations in values, concepts, and perceptions current in community archaeology. This required the researcher to conduct in-depth interviews and undertake multiple visits to community archaeology projects across the UK.

In order to reach a broader and more balanced perspective on community archaeology projects in the UK, studies of community archaeology projects were audited from different geographical localities, including urban and rural projects. Moreover, for comparative purposes, projects in the UK are to be assessed in relation to those taking place in the USA in order to reveal the influence of contrasting archaeological practices and socio-political contexts on the social impact of community projects. By researching a number of different contexts, and a number of different case studies, the aim is to show variability and diversity in community archaeology approaches. US case studies include Mitchell (Dakota), Muncy (Pennsylvania) and Annapolis (Maryland). Meanwhile, UK case studies have been selected at Shoreditch Park (London), Grosvenor Park (Chester), Hungate (York) and Brayford (Devon).

Preliminary results show that the ideals of community archaeology programmes, both in the US and the UK, often do not match expectations for the practical and perceived benefits for the communities. This applies to archaeologists, community volunteers, and non-participants. Moreover, this problem is ubiquitous regardless of the funding available, the context of the work, and the nature of the archaeology itself. It is hoped that a full assessment of this methodology and the data from both sides of the Atlantic will be completed by 2009 and subsequently published. This study will provide the first, long-awaited evaluation of community archaeology. 


\section{Conclusion}

Discussions of the values and benefits of public and community archaeology are increasingly prevalent in academic literature. The benefits of community involvement in archaeology are clearly espoused (Little, 2002; Jameson, 2004; Merriman, 2004). A complete realignment of public archaeology towards integrating communities into the archaeological process, in terms of both process and participation, has been advocated (e.g. Holtorf and Högberg, 2007; Holtorf, 2006). Some have aspired to concrete social outputs, ranging from the use of archaeology as an educational tool to its creation of a 'sense/pride of place' (English Heritage, 2000) and community spirit. There is a clear sense that archaeology is seen as a means of addressing social ills, for example by reducing crime and providing support for mental and physical disabilities. It is of critical importance to observe that these values are externally perceived, controlled, and promoted. They are not necessarily values in the heritage that are important or even relevant to the community themselves.

To date, the analysis of the success and value of community archaeology has focused on figures produced by quantitative methods, based on the number of visitors and participants, and the inclusion of ethnic and social groups. This is far from enlightening, as it does not assess how community archaeology affects social values and identities. In a discipline trying to validate this new paradigm of community archaeology, this is clearly a failing.

The discipline should take a more self-reflexive and anthropological approaches to the assessment of community archaeology. It is this kind of defined and effective methodology that holds the key to evaluating the sustainability and appropriateness of community archaeology in and for the future. This is essential, not just to justify the relevance of the paradigm of community archaeology but also for the survival of the profession of archaeology as a whole. For archaeology to survive on the government's political agenda, when funding for heritage is under increasing pressure, it must provide the public service it claims to provide. Furthermore, community archaeology must prove it does what it claims to do - meeting and adapting to the wants of the community - and must prove its broader values. This may only be done through internal self-reflexive appraisals and external ethno-archaeological approaches to the analysis of community archaeology. It is hoped that FS's project will begin the critical engagement between what community archaeology hopes and claims to achieve and what the public receives from the projects encapsulated by the term 'community archaeology'.

\section{Acknowledgements}

The authors would like to thank Penny Cunningham, Cornelius Holtorf, Yvonne Marshall, Sam Walls and the anonymous referee for critical comments on earlier drafts of this paper.

Faye Simpson would like to thank those who supported and helped to organise the Shoreditch project, including the core team at the Museum of London, Hedley Swain, John Shepherd, Roy Stephenson, Jackie Keily, the LAARC staff and volunteers, 
UCL students, Shoreditch Trust, Hackney Council, Time Team, and perhaps most importantly the local community for coming along and getting involved.

Howard Williams would like to thank Penny Cunningham, X-Arch project manager from April 2007, who oversaw the community activities for X-Arch in the 2007 field season. Thanks also go to Sam Walls (Exeter Graduate Fellow in Archaeologies of Memory) for site-managing the 2007 field season. Thanks also to Frances Griffith, Bill Horner, and Graham Tait for their support of the X-Arch project.

\section{References}

Accenture 2006 Capturing the public values of heritage: looking beyond the numbers. In: Clark, K. (ed.) The public value of heritage: the proceedings of the London conference 25-26th January 2006. English Heritage, Swindon, I9-22.

Aitken, R and F Simpson 2005 Shoreditch Park community excavation. In T. Nixon (ed.) MOLAS 2005: annual report, Museum of London. http://www.molas.org.uk/projects/annualReviews.asp?aryear $=2005 \&$ section $=\mathrm{I} \& \mathrm{c}$ ategory $=_{I}$ \& subsection $=\circ \&$ highlight $=$ shoreditch

All Party Parliamentary Archaeology Group 2003 The current state of archaeology in the United Kingdom: the first report of the All-Party Archaeology Group. All Party Archaeology Group, Society of Antiquities, London.

Blackburn, S 2006 Truth: a guide for the perplexed. Penguin, London.

Brown, T, S Hawken, F Griffith, L Franklin and C Hawkins 2004 Science, landscape archaeology and public participation: the Community Landscape Project, Devon, UK. Public Archaeology 3 2I7-226.

Edgeworth, M 2006 Foreword. In: Edgeworth, M (ed.) Ethnographies of archaeological practice: cultural encounters, material transformations. Altamira, Walnut Creek CA, ix.

English Heritage 2000 Power of Place: The Future of the Historic Environment. English Heritage for the Historic Environment Steering Group, London.

Faulkner, N 2005 In the beginning. In: Moshenska, G (ed.) A decade of discovery: the Sedgeford historical and archaeological research project 1996-2005. Heritage, Great Dunham, 6-7.

Hawkins, N 2000 Teaching archaeology without the dig: what's left? In Smardz, K and S J Smith (eds) The archaeology education handbook: sharing the past with kids. Altamira, Walnut Creek CA, 209-2I6.

Hodder, I (ed.) 2000 Towards reflexive method in archaeology: the example of Çatalhöyük. McDonald Institute for Archaeological Research, University of Cambridge, Cambridge.

Hodder, I (ed.) $200 \mathrm{I}$ Archaeological theory today. Polity, Cambridge.

Holtorf, C 2005 From Stonehenge to Las Vegas: archaeology as popular culture. Altamira, Walnut Creek CA.

Holtorf, C 2006 Archaeology is a brand! The meaning of archaeology in contemporary popular culture. Archaeopress, Oxford.

Holtorf, C and A Högberg 2007 Talking people: from community to popular archaeologies. Lund Archaeological Review II-I2 79-88.

Holtorf, C and H Williams 2006 Landscapes and memories. In: Hicks, D and M Beaudray (eds) Cambridge companion to historical archaeology. Cambridge University Press, Cambridge, 235-254.

Jameson, J 1997 Introduction. In: Jameson, J (ed.) Presenting archaeology to the public: digging for truths. Altamira, Walnut Creek CA, II-20.

Jameson, J 2004 Public archaeology in the United States. In: Merriman, N (ed.) Public archaeology. Routledge, London, 2I-58.

Lammy, D 2006 Community, Identity and Heritage. In Capturing the Public Values of Heritage: The Proceedings of the London Conference 25-26th January 2006. Swindon: English Heritage, pp. 65-69.

Liddle, P 1989 Community archaeology in Leicestershire museums. In: Southworth, E (ed.) Public service and private indulgence? The Museum Archaeologist 13. Society of Museum Archaeologists, Liverpool, 44-46.

Little, B L 2002 Archaeology as a shared vision. In: Little, B J (ed.) Public benefits of archaeology. University Press of Florida Press, Gainesville, 3-I9. 
Lucas, G 2004 Modern disturbances: on the ambiguities of archaeology. Modernism/Modernity II I09-I20. http:// muse.jhu.edu/journals/modernity/voor/Ir.lucas.pda

Marshall, Y 2002 What is community archaeology? World Archaeology 34(2) 2II-2I9.

Marshall, Y forthcoming Community archaeology. In: Cunliffe, B, C Gosden, and R Joyce (eds) The Oxford handbook of archaeology. Oxford University Press, Oxford.

McGimsey, C I972 Public archaeology. McGraw Hill, New York.

Merriman, N I99I Beyond the glass case: the past, the heritage and the public in Britain. Leicester University Press, Leicester.

Merriman, N 2004 Introduction: diversity and dissonance in public archaeology. In Merriman, N (ed.) Public archaeology. Routledge, London, I-I8.

Moser, S, D Glazier, J Philips, L N El Nemer, M S Mousa, S Richardson, A Conner and M Seymour 2002 Transforming archaeology through practice: strategies for collaborative practice in the Community Archaeology Project at Quseir, Egypt. World Archaeology 34(2) 220-248.

Moshenska, G 2005 Ten years of hard labour: an introduction. In: Moshenska, G (ed.) A decade of discovery: The Sedgeford historical and archaeological research project 1996-2005. Heritage, Great Dunham, 4-5.

Moshenska, G 2007a Unearthing an air-raid shelter at Edgeware Junior School. London Archaeologist II(9) $237-240$.

Moshenska, G 2007b Oral history in historical archaeology: excavating sites of memory. Oral History 35(I) 9I-97.

Moshenska, G, S Dhanjal, J Doeser, S Phillips and S Allen 2007 Community archaeology — against the odds. Current Archaeology 21334.

Newman, W L 1995 Social research methods: qualitative and quantitative approach. Allyn and Bacon, Boston MA.

Oswald, A 2007 Involving the community in field survey. The Archaeologist 63 20-2I.

Piccini, A and D Henson 2006 Survey of heritage television viewing 2005-2006. English Heritage, London.

Pluciennik, M (ed.) 200I Introduction. In: Pluciennik, M (ed.) The responsibilities of the archaeologist: archaeology and ethics. BAR International Series 98I. Oxford, Archaeopress I-8.

Rosenfeld, J 2006 Bruce Castle community dig: consultation and evaluation. Museum of London, London.

Schadla-Hall, T 1999 Editorial: public archaeology. European Journal of Archaeology 2(2) I47-I 58.

Simpson, F forthcoming The value of community archaeology: a comparative assessment. Doctoral thesis. University of Exeter, Exeter.

Simpson, F and J Keily 2005 Today's rubbish, tomorrow's archaeology: using nineteenth and twentieth century finds. The Archaeologist 58 26-27.

Smardz, K 2000 Digging with kids: teaching students to touch the past. In: Smardz, K and S J Smith (eds) The archaeology education handbook: sharing the past with kids. Altamira Press, New York, 234-248.

Streeter, K 2005 The case for community involvement. Unpublished MA thesis. University College London, London.

Tully, G 2007 Community archaeology: general methods and standards of practice. Public Archaeology 6(3) I $55-187$.

Walls, S and H Williams forthcoming Sacrificial landscapes on the home front: the archaeology of World War II commemoration in the South Hams, Devon.

Williams, H 2007a Stokenham 2006: interim report of excavations of prehistoric and medieval remains in Manor Field, Stokenham, Devon. Unpublished manuscript.

Williams, H. 2007b Introduction: themes in the archaeology of early medieval death and burial. In: Semple, S and H Williams (eds) Early medieval mortuary practices: Anglo-Saxon studies in archaeology and history 14. Oxford University School of Archaeology, Oxford, I-II.

Williams, H and S Turner 2005 Stokenham, Devon: archaeological survey and excavation in 2005. Excapades I(I) 44-64. http://www.uec.ac.uk/geography/excapades.htm

Williams, H \& E J L Williams 2007 Digging for the dead: archaeological practice as mortuary commemoration. Public Archaeology 6(I) 45-6I. 


\section{Notes on contributors}

Faye Simpson is a community archaeologist who has worked for the Portable Antiquities Scheme as a finds liaison officer and has directed community archaeology projects for the Museum of London. Faye is currently the Exeter Graduate Fellow in Community Archaeology within the Department of Archaeology at the University of Exeter. For her graduate fellowship, Faye is a project assistant for the X-Arch community archaeology project (2006-2009) and a doctoral candidate researching the efficacy and social context of community archaeology in the UK. Faye is a long-term contributor to the Time Team television series for Channel Four.

Correspondence to: Faye Simpson, Exeter Graduate Fellow in Community Archaeology, Department of Archaeology, University of Exeter, Laver Building, Exeter EX4 4QE, UK. Email: f.simpson@exeter.ac.uk

Howard Williams is a senior lecturer in archaeology at the University of Chester. His research focuses on mortuary archaeology, medieval archaeology, and the history of archaeology. He has directed archaeological research integrating community dimensions at Stokenham, Devon (2005-2007). Howard directed the X-Arch (Exploring Archaeology) Project funded by the Heritage Lottery Fund at the University of Exeter from April 2006 until January 2008. 